\title{
O SER E O NADA DE SARTRE: UMA "DESCOBERTA" FILOSÓFICA DOS "TEMPOS MODERNOS"
}

Cristina Diniz MENDONÇA ${ }^{1}$

- RESUMO: Este artigo indica que o "Ensaio de ontologia fenomenológica" de Sartre, O ser e o nada, poderia ser lido como uma recriação filosófica de uma experiência histórica crucial.

- PALAVRAS-CHAVE: Ontologia fenomenológica; filosofia da ação; liberdade; heroísmo; resistência.

Les vérités dites "éternelles" apparaissent dans et par l'Histoire.

Sartre, Cahiers pour une morale

Decorridos cinqüenta anos do lançamento de O ser e o nada, ressoa ainda nos diferentes tipos de balanço da obra o eco do mesmo refrão entoado desde os comentadores da primeira hora: trata-se de um livro de "pura reflexão filosófica", com portas e janelas fechadas para o mundo, escrito, no entanto, "curiosamente", numa época de virada histórica radical, durante a Segunda Guerra Mundial. Uma filosofia de sobrevôo, sem os pés no chão e sem território definido, semeando pensamentos de "pura ausência" histórica? Castelos de idéias que, sem raízes sociais, se formam e desmancham no ar? Tal caráter, à primeira vista paradoxal de uma obra de "filosofia pura" que se distancia da "realidade" num momento em que, como se lê nos Diánios de Guerra do próprio Sartre, "a realidade histórica impunha sua presença" aos contemporâneos (1983, p. 227), torna-se tanto mais surpreendente quando se pensa que a primeira elaboração de O ser e o nada ( $S N$ ) se encontra justamente nesses Diánios de Guerra (cujo propósito deliberado era captar a experiência histórica em curso) e que, além disso, intelectuais que participavam do movimento político de Resistência contra o nazismo declaram que o livro "tornou nosso universo transparente". Um "ensaio de ontologia fenomenológica" que torna visível o conteúdo de uma experiência política? Com efeito, um nó a ser desatado - o que implicaria uma genealogia da obra,

1. Departamento de Filosofia - Faculdade de Filosofia e Ciências - UNESP - 17525-900 - Marilia - SP. 
um estudo de sua forma particular e de suas relações com a totalidade das manifestações do momento histórico em que ela emerge. Tarefa de fôlego e paciência, vê-se logo, da qual sequer os preâmbulos poderiam ser expostos no âmbito acanhado deste artigo. Tentemos ao menos nos aproximar um pouco desse clássico da filosofia contemporânea (ainda que sem poder transpor o limiar necessário para evitar esquematizações brutais), contentando-nos apenas em puxar alguns dos fios que entrelaçam sua trama ontológica.

Ao leitor atento de $S N$ certamente não passará despercebida a arquitetura peculiar da obra, assentada em dois planos: o das "demonstrações" ontológicas, isto é, da descrição filosófica na acepção tradicional (e é nesse plano que os comentadores se detêm); e o plano da exemplificação - aqui, as ilustrações, os exemplos, são construídos com matéria histórica local, são figuras com conteúdo histórico definido (como na Fenomenologia do espínto, diga-se de passagem). É assim que ao longo da leitura de $S N$ vemos passar sob nossos olhos, como se fossem meros exemplos casuais (não-constitutivos, portanto, do "ensaio de ontologia fenomenológica") as figuras de "prisioneiros de guerra" (a guerra é justamente o exemplo privilegiado do livro), de líderes políticos da época, do ocupante alemão, do judeu perseguido, do Resistente, de uma cidade em estado de exceção, sob toque de recolher. Simples registro da hora histórica, exterior ao fio ontológico que está sendo urdido? Ocorre que em SN temos um movimento ininterrupto de passagem de um plano a outro (e nesse movimento de passagem está o lado mais vivo e interessante da obra), de tal maneira que a própria reflexão filosófica é tecida com materiais históricos da época. Todavia o problema permanece em aberto. Concedamos que $S N$, pretendendo apenas descrever essências filosóficas (pois não é outro o seu propósito), o faça com figuras do mundo real. Mas em que medida esse registro da hora histórica, movendo-se assim num nível tão conjunturalmente rente aos fatos, se articula internamente com as "demonstrações" ontológicas? Em que termos se daria a reapropriação filosófica desses exemplos? Esse o ponto delicado.

No interior do movimento de vai-e-vem entre os dois planos de $S N$ (ao longo do qual se misturam materiais heteróclitos: Husserl, Heidegger, Hegel, sem falar de Malraux, dos clássicos do modernismo americano e de Kafka, tudo isso amalgamado a assuntos da vida cotidiana) se dá um outro movimento: as figuras que compõem a trama do livro vão sendo transformadas (como numa intriga teatral - dramática, no caso) e tal transformação vai permitindo a passagem de um momento de pura negatividade, o momento negativo da alienação (que resulta do olhar do outro e da própria estrutura da consciência que tem seu ser fora de si mesma) ao sentido "positivo" da alienação, outro aspecto da "descoberta" da figura de uma liberdade que é libertação. Nesse duplo sentido da alienação está o nervo por onde passam todos os problemas de $S N$.

O momento negativo da alienação descreve uma subjetividade impotente diante da força das coisas - uma consciência cujo ser foi jogado no mundo das coisas: "je 
suis dehors", "se métamorphoser en chose" (1943, p. 468, 672). O interessante é que nesse nível, ao descrever esse estado de liquidação do indivíduo, as análises de $S N$, correndo no sentido do espírito do tempo, chegam a reproduzir o tom (e até mesmo o vocabulário) dos relatos de época. Naquela conjuntura sombria da guerra e da ocupação da França, momento em que, como dirá Sartre mais tarde, "a pressão histórica esmagava" (1948, p. 236) e em que a alienação atinge uma "situação-limite" (na linguagem de $S N$ ), nada mais "realista" do que as descrições, constitutivas do "ensaio de ontologia" sartriano, de um estado de desintegração do sujeito e do mundo ("le monde se désintègre"). Sob este prisma, poder-se-ia dizer que as "deformações" (por assim dizer) filosóficas da realidade terminariam por descrever, de forma sibilina, um estado de coisas "deformado", isto é, que perdeu sua forma tradicional. ${ }^{2}$ É como se algo do mundo "concreto" conseguisse romper a muralha especulativa e impusesse sua presença. Num certo sentido (mas veremos que as análises do livro não são de mão única), $S N$ permitiria ser lido como a forma lógico-abstrata de uma alienação real (cuja experiência-limite, segundo as análises posteriores de Sartre, é o campo de concentração). Se invertermos os termos tradicionais do problema, poderíamos talvez dizer que $S N$ é concreto porque é abstrato - a abstração, naquele momento, expõe um aspecto da verdade histórica, ou melhor, é a própria realidade social que se tornara abstrata para os homens da época: "Paris n'avait plus qu'une existence abstraite", escreve Sartre em seu balanço sobre a ocupação (1949, p. 27). Com o objetivo de entender $\mathrm{o}$ abstrato concretamente, o autor acabaria captando o concreto abstratamente ("não são exemplos, é a própria vida", confidenciava Sartre a J.-T. Desanti a respeito das ilustrações de $S N^{3}$ ). Mas se assim for, embora à primeira vista nada autorize a suspeitar que o fio que está sendo tecido em $S N$ não é meramente ontológico, torna-se possível vislumbrar no interior da obra rastros do movimento histórico real, e, nessa medida, desvelar seu "conteúdo de verdade objetiva e social" (a expressão é de Adorno).

Do coração do raciocínio especulativo uma janela abre-se para o mundo? Sim, mas o que vemos por essa janela não é o mero retrato de "fatos" históricos, são retratos retocados pelo trabalho de recriação filosófica (no mesmo sentido que Michelet afirma que os retratos das personagens de sua Histónia da Revolução Francesa vão sendo, como os diferentes auto-retratos de Rembrandt, retocados pelo tempo). Nesse resultado filosófico, nesse retrato retocado, não se pode mais distinguir o que é "real" e o que é ficção - trata-se antes de "ficções" necessárias. (Já o personagem central de Náusea, Roquentin, contrapondo-se à historiografia tradicional, afirma que o trabalho de construção, ou de reconstrução, faz do passado, resgatado pela memória, um misto de souvenirs e de fictions - mas é justamente na ficção que a realidade pode ser mais bem captada, sugere Roquentin.) É ao longo dessa recriação filosófica que é construído

2. Procurando sugerir a necessidade histórica do surgimento do "existencialismo", Merleau-Ponty escreve: "essa filosofia é a expressão de um mundo deslocado" (1980, p. 308).

3. Desanti, J.-T., entrevista a Michel Contat, Le Monde, 2.7.1993. 
o sentido positivo da alienação, resultado do delineamento da figura central da obra: a liberdade.

Com efeito, só se compreende o duplo sentido da alienação em $S N$ quando se tem em mente as condições nas quais a liberdade entra em cena no livro: sua figura radiante e luminosa torna-se visível ao contrastar com o fundo escuro e sombrio da não-liberdade. Mais precisamente: é o estado viscoso de não-liberdade que vai secretando a figura da liberdade - a liberdade floresce assim à sombra da não-liberdade. Aparecendo, inicialmente, como resultado inelutável de um processo de alienação, a não-liberdade vai se tornando condição de possibilidade do surgimento da liberdade - o ponto extremo da alienação coincide com o ponto de nascimento da não-alienação. E de dentro mesmo daquele estado de alienação, de não-liberdade, impotência e resignação nasce a liberdade como nova figura da fatalidade: é da idéia de condenação pelo olhar do outro (que nos converte em objetos - "nous ne pouvons échapper à cette aliénation...", 1943, p. 583) que vemos surgir o famoso "condamnés à être libres". Transformando pois a condenação à alienação em condenação à liberdade, as análises de $S N$ fazem assim o fatalismo engendrar - paradoxalmente a liberdade.

Esse processo de constituição da figura da liberdade passa necessariamente pelas idéias de tomada de consciência (da não-liberdade), de "escolha" e de mudança (changement). Mas todas essas dimensões essenciais da liberdade remetem à idéia de resistência, que se delineia, no interior das análises de $S N$, como o verdadeiro fundamento da liberdade: "Il ne peut y avoir de pour-soi libre que comme engagé dans un monde résistant" (1943, p. 540). Dizíamos que a liberdade nasce das entranhas da não-liberdade. Apressemo-nos em acrescentar: só pode fazê-lo, por um ato de resistência contra o estado de não-liberdade - esse movimento que leva a não-liberdade a solicitar sua própria recusa é realizado por um trabalho interno de resistência. O doloroso parto dessa liberdade que nasce "dans l'angoisse "(1943, p. 615) é feito através da resistência àquilo que a cerceia (e não a despeito dela). Numa palavra: a resistência é a parteira da liberdade.

Compreendamos o sentido desse resultado do processo de inversão que permite o nascimento da liberdade: em vez de resignar-se complacentemente à força da alienação, ao estado de não-liberdade, em vez de eternizar tal estado de coisas vigente, a análise de $S N$ subverte os termos do problema e, heroicizando a consciência, apela à luta, à emancipação: "il y a 'quelque chose' à détruire pour me libérer" (1943, p. 462). Mas é aqui, no coração mesmo dessa passagem especulativa, que faz a liberdade renascer de um ato de resistência capaz de metamorfosear a impotência da subjetividade em heroísmo da consciência, que se poderia reconhecer a passagem histórica: do "fatalismo", da "resignação" e da "impotência" que decorrem da derrota de 1940 (tal como as memórias de época descrevem o estado de espírito hegemônico entre os contemporâneos) ao heroísmo da Resistência. Essa subversão especulativa (que reconstrói filosoficamente uma "subversão" histórica) só pôde ser feita a partir de materiais extraídos da prática política da Resistência, como mostram os exemplos 
usados pelo autor: "le fuyard" versus "l'homme qui résiste" (1943, p. 498); "je puis reagir contre ces interdictions..." (1943, p. 582); "libérer la Pologne, lutter pour le prolétaniat" (1943, p. 609). Essa liberdade que, após um longo período de incubação, renasce por um ato de resistência heróica ("projet de supression de cet asservissement réel" e de "reconquérir la liberté", 1943, p. 462) não é senão, se nossa leitura procede, a reconciliação filosófica com o espírito da Resistência contra o nazismo.

Vê-se assim que SN permitiria também uma outra direção de leitura. Com efeito, havíamos dito que apenas num certo sentido o livro poderia ser lido como a descrição filosófica de um estado de alienação real. Essa é apenas uma meia verdade. Num outro sentido, a análise sartriana, transformando o negativo em positivo, convertendo a perda em ganho, vai tecendo, com detalhes, a possibilidade da "salvação" no interior mesmo das relações que engendram a alienação, ou melhor, é a própria alienação que é transmudada em libertação. ${ }^{4}$ Esse resultado positivo dos "caminhos da liberdade" em SN - do "condamnés à l'alienation" ao "condamnés à changer" heroicamente o existente - é o outro aspecto do heroísmo dramático da Resistência (um "programme héroique" que "s'est réalisé point par point sous mes yeux", conforme dirá Sartre mais tarde ${ }^{5}$ ). Deste ângulo, o livro poderia ser lido como apelo à Resistência, apelo ao ato "libre et volontaire" de resistência (esse apelo ao ato decisório, um ato de vontade realizado por um sujeito livre, resgata, através da filosofia da ação de Kojève, o convite fichteano à liberdade, à escolha de uma humanidade emancipada).

Encontramos aqui o nó que entrelaça os verdadeiros problemas do livro: uma espécie de curto-circuito que faz com que suas noções abstratas terminem por captar um processo de mudança social. Compreende-se mais claramente agora em que sentido seria possível dizer que $S N$ não apenas descreve um estado real de coisas, não apenas registra a hora histórica ("il suffit que j'aie lu les journaux...", 1943, p. 573), mas sobretudo reconstrói o processo de engendramento do mundo da liberdade heróica da Resistência. Melhor: ao recriar filosoficamente aquele estado real do mundo, as análises sartrianas terminariam vislumbrando flashes do processo de gestação do mundo novo ainda nas entranhas do velho. Distanciando-se (justamente por tratar-se de um processo de recriação) do presente político, que todavia as sustenta, conseguem antecipar sua superação. Em suma: o mesmo movimento que descreve um estado de coisas, capta o processo de seu perecimento. É como se do fundo de uma conjuntura histórica sombria as análises de $S N$ tivessem conseguido entrever, através das frestas daquele mundo que se quebrava, o delineamento da

4. Tal movimento transformador é feito pela mediação de uma temporalidade que "cura" ("temps qui guérit"). Não por acaso o estudo clas "relações concretas com o outro" culmina no anúncio da "morale de la délivrance et du salut" - essa passagem, colocada em nota, aparentemente externa ao novelo ontológico do livro, não chama nunca a atenção dos comentadores: na leitura de Marcuse, por exemplo, essa "morale de la délivrance et du salut" seria uma idéia fora do lugar, isto é, própria do último Sartre e não de $S N$, uma obra em que o pensamento está mergulhado na "noite do desespero" (1970, p. 216)

5. Sartre, J-P., "Un promeneur dans Paris insurgé", série de sete artigos sobre a Libertação de Paris, Combat, 28.8.1944, 29.8.1944, 30.8.1944, 31.8.1944, 1.9.1944, 2.9.1944, 4.9.1944. 
fisionomia de uma nova época, dos "Tempos Modernos" então em marcha, cujo espírito puderam surpreender (antecipando-se especulativamente): liberdade - ao fazê-lo, tomam filosoficamente a dianteira do movimento político de luta pela liberdade (o que explica a recepção do livro pelos intelectuais da Resistência). Vê-se, assim, que em vez de fantasmagoria, ou pura metafísica, a filosofia da liberdade desenvolvida em SN é resposta a uma determinada circunstância histórica. O autor erige uma conjuntura histórica precisa em instância de demonstração filosófica - é esse vínculo interno entre abstração filosófica e situações concretas do mundo que caracteriza o livro. Numa palavra: o "verdadeiro conteúdo" de SN é a guerra, a ocupação e a Resistência.

À luz desse horizonte histórico, compreende-se melhor o voluntarismo e o heroísmo dramático que a meu ver caracterizam $S N$. Fora do contexto daquela época - "uma época que foi, como todos os momentos revolucionários, propícia às premissas e termos do voluntarismo" ("houve iniciativas heróicas e atos de vontade entre 1936 e 1946"), conforme afirma Thompson (1981, p. 87), seria impensável tal resposta voluntarista do herói sartriano. (Um "herói" na Idade de Kafka? Recorde-se de que Hegel já demonstrara a impossibilidade do herói no mundo prosaico do capitalismo em Cervantes, por exemplo, já temos o herói em paródia.) A experiência da guerra e da Resistência (em particular a batalha heróica de Stalingrado, exaltada pelos contemporâneos como uma verdadeira experiência épica) permitiu uma reativação de temas do heroísmo clássico (temas que Malraux, aliás, já recolocara na ordem do dia à luz da guerra civil espanhola). É essa luta heróica da Resistência contra o nazismo que dá sentido à assimilação sartriana do heroísmo literário de Malraux e do heroísmo filosófico de Heidegger. Esquematizando: SN capta (e mesmo antecipa) filosoficamente um momento de virada histórica: a partir de Stalingrado a palavra de ordem "Da Resistência à Revolução" começa a se impor - a Revolução mundial poderia finalmente sair da guerra (assim como em $S N$ a liberdade sai de dentro da não-liberdade). $\mathrm{Na}$ encruzilhada de dois mundos, o "ensaio de ontologia fenomenológica" de Sartre (cujo final de redação, início de 1943, coincide com a vitória de Stalingrado) parece justamente anunciar a superação de um estado de não-liberdade e o advento dos "Tempos Modernos" - uma época marcada pela "puissance de la liberté" (tal como Sartre define mais tarde aquela conjuntura de efervescência revolucionária que culmina na insurreição parisiense de 1944 - esse "Apocalipse da Liberdade", nas palavras do autor). O livro termina justamente com uma apologia da liberdade - nessa apologia, nesse hino à liberdade, podem-se ouvir os ecos da batalha de Stalingrado. Nesta perspectiva, a obra estaria reescrevendo, de forma dramática, uma experiência histórica igualmente dramática (é da generalização teórica dessa experiência que virá a filosofia sartriana da Revolução). É a própria História que está sendo reconstruída lá dentro (de forma mitológica, certamente, mas isso não impede que veicule problemas reais). Fora daquele "monde résistant", para usar a linguagem do livro, nosso olhar retrospectivo sobre $S N$ correria o risco (e são muitos os que hoje por aí derrapam) de anacronismo, e mais, de apresentar a obra como um ensaio de ontologia brilhante, 
mas cujo sentido parece inextricável diante dos problemas teóricos colocados pelo curso do mundo moderno.

Voltamos assim ao ponto de onde partimos: não é que a filosofia elaborada em SN não tivesse os pés no chão, é que o chão histórico acabara de desabar: "il nous parut que le sol allait manquer sous nos pas", escreve Sartre em seu balanço daquele período (1948, p. 242). ${ }^{6}$ Grau zero da história, ou "história em suspenso", segundo a análise de Merleau-Ponty - uma época privilegiada de transparência em que "se tornara impossível ignorar a matéria social, assim como um doente já não pode ignorar seu corpo" (1975, p. 203). Momento de euforia e de "descoberta" da História (como no início da filosofia clássica alemã diante da Revolução Francesa), do "moderno" "idées, valeurs, tout fut bousculé", afirma Simone de Beauvoir, referindo-se àquela "guerre qui avait tout remis en question" (1963, p. 100). Era preciso tudo reinventar (o que tornou possível a ruptura com a tradição, ou seja, com o "idealismo" da filosofia universitária da Terceira República, contra o qual justamente se desencadeia o movimento "rumo ao concreto", palavra de ordem do "existencialismo" em sua fase ascendente). É essa reinvenção, cujo resultado encarna a "idade de ouro da consciência histórica" local, que está sendo preparada filosoficamente em $S N$ - não por acaso o livro se fecha apontando os limites da ontologia e, ao mesmo tempo, abrindo caminho para a elaboração de um outro método de investigação da realidade humana (o itinerário do pensamento sartriano não é senão a busca de uma forma filosófico-literária que possa dar conta do tempo presente - é sobretudo na forma do ensaio que o autor, após o abandono do projeto de construir uma moral, passará a fazer uma espécie de "crítica da filosofia que não quer abrir mão da filosofia", mas isso já é assunto para uma outra conversa).

Fechemos estas notas sobre $S N$, sublinhando o descompasso entre a intenção e o resultado da obra: Sartre não queria senão descrever as estruturas universais da realidade humana, mas acaba (inconscientemente) escrevendo para seus contemporâneos, escrevendo para sua época e sobre sua época (daí o sucesso do livro - uma filosofia da ação e da liberdade heróica, como convinha ao espírito daqueles tempos). Mas é justamente nesse descompasso que está sua fecundidade.

MENDONÇA, C. D. Sartre's L'Être et le Néant: a philosophical discovery of "Modern Times". Trans/Form/Ação, São Paulo, v. 17, p. 105-111, 1994.

- ABSTRACT: This article defends the view that Sartre's "phenomenological ontology essay", L'Être et le Néant, could be understood as a philosophical re-creation of a crucial historical experience.

- KEYWORDS: Ontological phenomenology; philosophy of action; liberty; heroism; Resistance.

6. São idênticas as palavras com as quais Camus descreve, em La Peste, o sentimento hegemônico entre os homens daquela época: "ils sentaient le sol manquer sous leurs pas" (1947, p. 248) 


\section{Referências bibliográficas}

1 BEAUVOIR, S. La force des choses. Paris: Gallimard, 1963, v. I, II.

2 CAMUS, A. La peste. Paris: Gallimard, 1947.

3 MARCUSE, H., L'Existentialisme - a propos de L'Être et le Néant de Sartre. In: Culture et société. Paris: Les Editions de Minuit, 1970.

4 MERLEAU-PONTY, M., Em torno do marxismo. São Paulo: Abril Cultural, 1975. (Os Pensadores)

5 . Humanisme et Terreur. Paris: Gallimard, 1980.

6 SARTRE, J-P., Les camets de la drôle de guerre. Paris: Gallimard, 1983.

7 . L'Être et le Néant. Paris: Gallimard, 1943.

8 . Situations, II. Paris: Gallimard, 1948.

9 . Situations, III. Paris: Gallimard, 1949.

10 . Un promeneur dans Paris insurgé. Combat, 28, 29, 30 e 31 ago. 1944; 1 set., 2 e 4 set. 1944. (Série de 7 artigos sobre a Libertação de Paris).

11 THOMPSON, E. P. A miséria da teonia. Rio de Janeiro: Zahar, 1981. 